\title{
Reconsidering the Welfare Cost of Inflation in the US: A Nonparametric Estimation of the Nonlinear Long-Run Money Demand Equation using Projection Pursuit Regressions
}

\author{
Rangan Gupta\# and Anandamayee Majumdar*
}

ABSTRACT

This paper, first, estimates the appropriate, log-log or semi-log, linear long-run money demand relationship capturing the behavior US money demand over the period of 1980:Q1 to 2010:Q4, using the standard linear cointegration procedures found in the literature, and the corresponding nonparametric version of the same based on Projection Pursuit Regression (PPR) methods. We then, compare the resulting welfare costs of inflation obtained from the linear and nonlinear money demand cointegrating equations. We make the following observations: (i) The appropriate money demand relationship for the period of 1980:Q1 to 2010:Q4 is captured by a semi-log function; (ii) Based on the estimation of semi-log cointegrating equations, the welfare cost of inflation was found to at the most lie between 0.0131 percent of GDP to 0.2186 percent of GDP for inflation rates between 0 percent and 10 percent, and; (iii) In comparison, the welfare cost of inflation obtained from the semi-log non-linear long-run money demand function, derived using the PPR method, for 0 to 10 percent of inflation ranges between 0.4930 to 1.9468 percent of GDP. However, the standard errors associated with the welfare cost estimates obtained from PPR relative to the linear models tend to indicate that the nonlinear money demand provides more precise estimates of the welfare costs primarily for higher rates of inflation.

Keywords: Cointegration; Money Demand; Projection Pursuit Regression; Welfare Cost of Inflation.

JEL Classification: E31; E41; E52.

\footnotetext{
\# To whom correspondence should be addressed. Department of Economics, University of Pretoria, Pretoria, 0002 , South Africa. Email: Rangan.Gupta@up.ac.za.

* Department of Biostatistics, University of North Texas Health Science Center, School of Public Health, Fort Worth, Texas, 76107, USA. Email: anandamayee.majumdar@gmail.com.
} 


\begin{abstract}
This paper, first, estimates the appropriate, log-log or semi-log, linear long-run money demand relationship capturing the behavior US money demand over the period of 1980:Q1 to 2010:Q4, using the standard linear cointegration procedures found in the literature, and the corresponding nonparametric version of the same based on Projection Pursuit Regression (PPR) methods. We then, compare the resulting welfare costs of inflation obtained from the linear and nonlinear money demand cointegrating equations. We make the following observations: (i) The appropriate money demand relationship for the period of 1980:Q1 to 2010:Q4 is captured by a semi-log function; (ii) Based on the estimation of semi-log cointegrating equations, the welfare cost of inflation was found to at the most lie between 0.0131 percent of GDP to 0.2186 percent of GDP for inflation rates between 0 percent and 10 percent, and; (iii) In comparison, the welfare cost of inflation obtained from the semi-log non-linear long-run money demand function, derived using the PPR method, for 0 to 10 percent of inflation ranges between 0.4930 to 1.9468 percent of GDP. However, the standard errors associated with the welfare cost estimates obtained from PPR relative to the linear models tend to indicate that the nonlinear money demand provides more precise estimates of the welfare costs primarily for higher rates of inflation.
\end{abstract}

Keywords: Cointegration; Money Demand; Projection Pursuit Regression; Welfare Cost of Inflation.

JEL Classification: E31; E41; E52.

\title{
1. INTRODUCTION
}

In a recent paper, Ireland (2009), using quarterly US data covering the period of 1980:Q1-2006:Q4, indicates: (i) The null of unitary long-run income elasticity of money cannot be rejected; (ii) Money demand functions can, thus, be expressed as capturing relationships between the nominal moneyincome ratio and the nominal interest rate; (iii) Though, the logarithm of the money-income ratio, the logarithm of the nominal interest rate, and the nominal interest rate are all integrated of order one, based on the Phillips and Ouliaris (1990) and Stock and Watson (1993) tests of linear cointegration, the appropriate money demand relationship for the period of 1980:Q1 to 2006:Q4 is captured by a semi-log function; i.e., a linear functional form relating the logarithm of money demand and the nominal interest rate, since no cointegrating relationship could be obtained between the logarithm of the nominal money-income ratio and the nominal interest rate (i.e., the $\log -\log$ money demand function), and; (iv) Based on the estimation of semi-log cointegrating equations, obtained under the Phillips and Ouliaris (1990) and Stock and Watson (1993) approaches, the welfare cost of inflation was found to at the most lie between 0.0140 percent of GDP to 0.2320 percent of GDP for inflation rates between 0 percent and 10 percent, mimicking comparable welfare estimates obtained for the US by Fischer (1981) and Lucas (1985). 
With the $(\mathrm{X}, \mathrm{Y})$ plane capturing the nominal interest rate and the nominal money-income, Figure 1 superimposes the five alternative semi-log cointegrating relationships obtained by Ireland (2009) on the scatter plot of the actual data. Note that, while one of the cointegrating equation is based on the Phillips and Ouliaris (1990) approach, the remaining four are obtained under alternative assumptions regarding the lag-structure of the model $^{1}$ from Dynamic Ordinary Least Squares (DOLS) method $^{2}$ proposed by Stock and Watson (1993). As can be seen, the semi-log money demand relationship misses quite a bit of the actual data, with all the cointegrating relationship being virtually indistinguishable from each other. When we extend the data till 2010:Q4, re-estimate and re-plot the five new cointegrating relationships with the scatter plot of the data on nominal money-income ratio and the nominal interest rate, nothing much changes. The linear long-run relationships continue to miss quite a bit of the data and, especially the current behavior of the money demand under the virtually zero nominal rate of interest observed in the data since 2008:Q4. Note that, using the updated data till 2010:Q4, we obtained similar qualitative and quantitative results ${ }^{3}$ as obtained by Ireland (2009), and as summarized above in (i) through (iii).

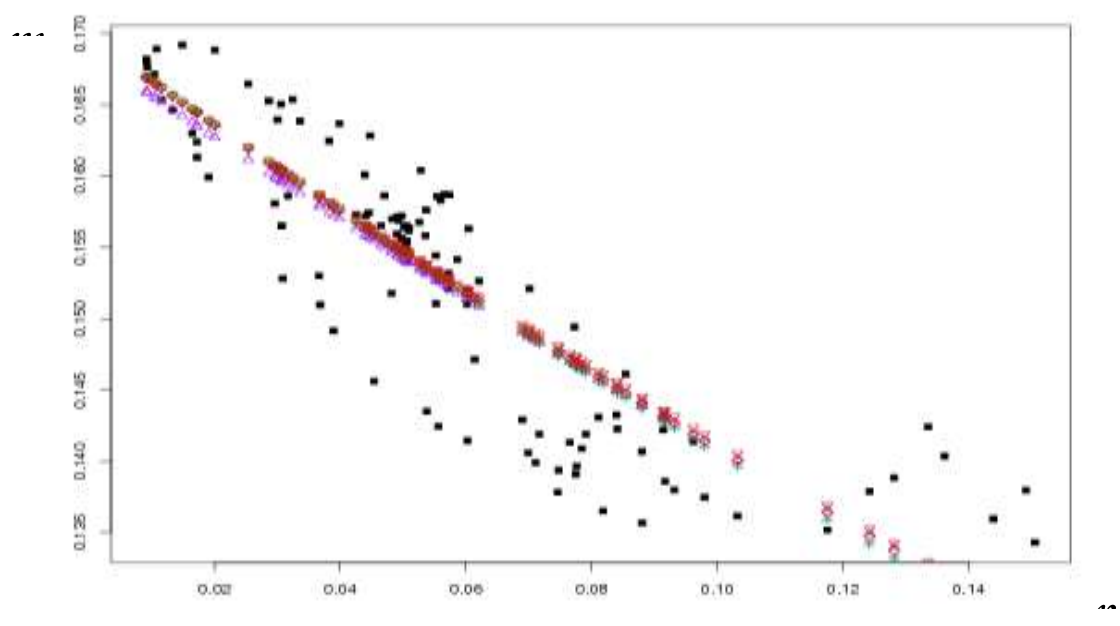

Figure 1. Cointegrating Relationships between $\ln (m)$ and $r(1980$ Q1-2006Q4): Original Data [Black solid square signs]; $\ln (m)=-1.7800-1.794 *^{*}$ [Purple triangle signs with an angle facing upward]; $\ln (m)=-1.7731-1.8939 *^{*}$ [Blue plus signs]; $\ln (m)=-1.7719-1.9013 * r$ [Green cross signs]; $\ln (m)=-1.7732-1.8639{ }^{*} r$ [Red diamond signs]; $\ln (m)=-1.7738-1.8261 * r$ [Brown triangle signs with an angle facing downward]. Refer to Section II of Ireland (2009) for further details.

${ }^{1}$ Please refer to Section II of Ireland (2009) and Section 3 of the current paper for further details on the specifications of the DOLS model.

${ }^{2}$ Please refer to Section 3 of the current paper for further details.

${ }^{3}$ Please refer to Section 4 of the current paper for further details. 


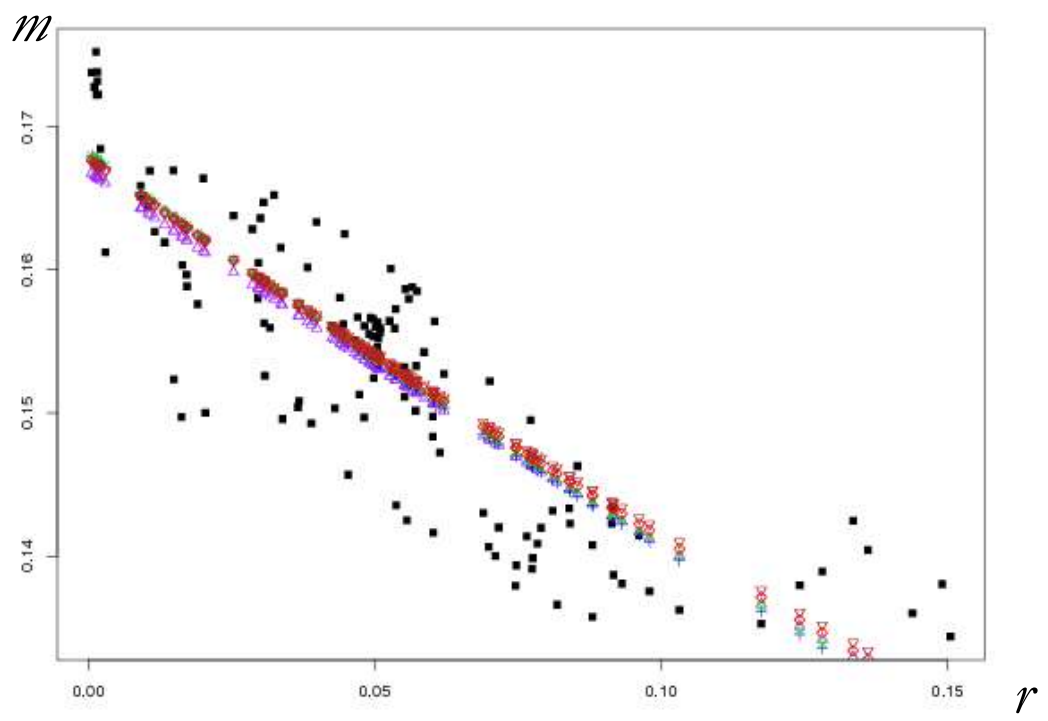

Figure 2. Cointegrating Relationships between $\ln (m)$ and $r$ (1980Q1-2010Q4): Original Data [Black solid square signs]; $\ln (m)=-1.7904-1.7027^{*} r$ [Purple triangle signs with an angle facing upward]; $\ln (m)=-1.7831-1.7951^{*} r$ [Blue plus signs]; $\ln (m)=-1.7829-1.7768^{*} r$ [Green cross signs]; $\ln (m)=-1.7850-1.7186^{*} r$ [Red diamond signs]; $\ln (m)=-1.7854-1.6835^{*} r$ [Brown triangle signs with an angle facing downward]. Refer to Section 4 of the current paper for further details.

Against this backdrop, we attempt to obtain a nonlinear cointegrating money demand relationship, over the period of 1980:Q1 to 2010:Q4, based on Projection Pursuit Regression (PPR) outlined in Friedman and Stuetzle (1981), that fits the data better, especially the current money demand behavior under negligible nominal rate of interest. In this regard we follow Vinod (1998), and carry out a nonparametric PPR estimation of the semi-log model. Once a nonlinear cointegrating money demand relationship is obtained, we derive the welfare cost of inflation from this framework, and compare the corresponding estimates of the same obtained under the linear long-run money demand relationships. Though, Vinod (1998) used the PPR method to estimate a non-linear longrun money demand relationship for the US economy using annual data covering the period of 19001989 , this is, to the best of our knowledge, the first attempt to obtain the welfare cost of inflation for the US economy based on a nonparametric long-run money demand function. The remainder of the paper is organized as follows: Section 2 provides the basics of the theoretical issues regarding the estimation of the welfare cost of inflation both under linear and nonparametric frameworks. Section 3 discusses the data, while, Section 4 presents the empirical results, including the calculation of the welfare cost estimates. Finally, Section 5 concludes. 


\section{THE THEORETICAL FOUNDATIONS}

As indicated by Lucas (2000), money demand specification is vital in determining the appropriate size of the welfare cost of inflation. Lucas (2000) contrasts between two competing specifications for money demand. One, inspired by Meltzer (1963), relates the natural logarithm of $m$, the ratio of money balances to nominal income, and the natural logarithm of a short-term nominal interest rate $r$. Formally, this can be expressed as follows:

$\ln (m)=\ln (A)-\eta \ln (r)$

where $A>0$ is a constant and $\eta>0$ measures the absolute value of the interest elasticity of money demand. Another specification, adapted from Cagan (1956), links the log of $m$ to the level of $r$ via the following equation:

$\ln (m)=\ln (B)-\xi r$

where $B>0$ is a constant and $\xi>0$ measures the absolute value of the semi-elasticity of money demand with respect to the interest rate. Note, both these specifications impose unitary income elasticity of money demand.

By applying the methods outlined in Bailey (1956), Lucas (2000) transformed the evidence on money demand into a welfare cost estimate. Note Bailey (1956) described the welfare cost of inflation as the area under the inverse money demand function, or the "consumers's surplus", that could be gained by reducing the interest rate to zero from an existing (average or steady-state) value. So if $m(r)$ is the estimated function, and $\psi(m)$ is the inverse function, then the welfare cost can be defined as: $w(r)=\int_{m(r)}^{m(0)} \psi(x) d x=\int_{0}^{r} m(x) d x-r m(r)$

Alternatively, this implies integrating under the money demand curve as the interest rate rises from zero to a positive value to obtain the lost consumer surplus and then deducting off the associated seigniorage revenue $r \times m$ to deduce the deadweight loss.

Since the function $m$ has the dimensions of a ratio to income, so does the function $w$. The value of $w(r)$, represents the fraction of income that people need, as compensation, in order to be indifferent between living in a steady-state with an interest rate constant at $r$ or an identical steady state with an interest of close or equal to zero. Given this, Lucas (2000) shows that when the money demand function is given by (1) or is $m(r)=A r^{-\eta}$, the welfare cost of inflation as a percentage of GDP is obtained as follows:

$$
w(r)=A\left(\frac{\eta}{1-\eta}\right) r^{1-\eta}
$$


While, for a semi-log money demand specification i.e., $m(r)=B e^{-\xi r}, w(r)$ is obtained by the following formula:

$$
w(r)=\frac{B}{\xi}\left[1-(1+\xi r) e^{-\xi r}\right]
$$

As can be seen from (4) and (5), an estimate of the interest elasticity of money demand is crucial in evaluating the welfare cost of inflation, and, hence, we first need to obtain the long-run relationship between the ratio of money balance to income and a measure of the opportunity cost of holding money, captured by a short-term nominal interest rate.

Note that in the case when the nonlinear long-run money demand function is nonparametrically estimated using the PPR method ${ }^{4}, w(r)$ does not have a closed-form, and, hence, needs to be obtained numerically. Our approach is based on Monte Carlo integration. For any value of given interest rates, $r$, in the range of the data, we obtain $w(r)$ as follows:

$$
w_{N}(r) \approx \frac{1}{N} \sum_{i=1}^{N} m\left(x_{i}\right)-r \times m(r)
$$

where $N$ is chosen to be a very large number, and $x_{i} i=1, \ldots, N$ are independent identically distributed observations from the Uniform distribution on the interval $(0, r)$. The Weak Lawof Large Numbers ensures that $w_{N}(r)$ converges in probability to $w(r)$, so if $N$ is large enough, we can assure, with large confidence, that we are close to the limit. To obtain the estimates of $w(r)$ for the semi-log model estimated under the PPR method, we used $N=100,000$, which can be considered large enough.

\section{DATA}

In this study, we use quarterly data time series data from the first quarter of 1980 (1980:Q1) to the last quarter of 2010 (2010:Q1), and are obtained from the Federal Reserve Bank of St. Louis FRED database, except that the series for the measure of money supply (M1) is adjusted by adding back the funds removed by retail deposit sweep programs using estimates described in Cynamon et al., (2006). Hence, as in Ireland (2009) we too measure the money stock based on the M1RS aggregate defined by Cynamon et al., (2006). Nominal income and the nominal interest rates are measured by nominal GDP $(Y)$ and the three-month US Treasury bill rate $(r)$, respectively. All series, except for the Treasury bill rate were used in their seasonally adjusted form. When instead of using the money income ratio $(m=M 1 R S / Y)$, we used real money balances $(M / P)$ and real GDP $(Y / P)$

\footnotetext{
${ }^{4}$ Basics of the PPR method have been provided in the Section 3 and additional details appear in the Appendix of the paper.
} 
independently in the regressions, the corresponding nominal series for M1RS and GDP were divided by the GDP deflator $(P)$.

Table 1- Phillips-Perron Unit Root Test Results

\begin{tabular}{|c|c|c|c|c|}
\hline \multirow[t]{10}{*}{$\ln (m)$} & $\hat{\mu}$ & $\hat{\rho}$ & $q$ & $\mathrm{Z}_{\mathrm{t}}$ \\
\hline & -0.014 & 0.9916 & 0 & -0.436 \\
\hline & & & 1 & -0.8808 \\
\hline & & & 2 & -1.1449 \\
\hline & & & 3 & -1.3313 \\
\hline & & & 4 & -1.4398 \\
\hline & & & 5 & -1.5051 \\
\hline & & & 6 & -1.5475 \\
\hline & & & 7 & -1.5625 \\
\hline & & & 8 & -1.5527 \\
\hline \multirow[t]{10}{*}{$\ln (r)$} & $\hat{\mu}$ & $\hat{\rho}$ & $\mathrm{q}$ & $\mathrm{Z}_{\mathrm{t}}$ \\
\hline & -0.007 & 1.0112 & 0 & 0.5784 \\
\hline & & & 1 & 0.2877 \\
\hline & & & 2 & 0.0903 \\
\hline & & & 3 & -0.0992 \\
\hline & & & 4 & -0.3047 \\
\hline & & & 5 & -0.3949 \\
\hline & & & 6 & -0.4452 \\
\hline & & & 7 & -0.473 \\
\hline & & & 8 & -0.4812 \\
\hline \multirow[t]{10}{*}{ r } & $\hat{\mu}$ & $\hat{\rho}$ & $q$ & $\mathrm{Z}_{\mathrm{t}}$ \\
\hline & 0.0013 & 0.9547 & 0 & -2.0403 \\
\hline & & & 1 & -2.1245 \\
\hline & & & 2 & -2.1292 \\
\hline & & & 3 & -2.1476 \\
\hline & & & 4 & -2.1379 \\
\hline & & & 5 & -2.1343 \\
\hline & & & 6 & -2.1366 \\
\hline & & & 7 & -2.1078 \\
\hline & & & 8 & -2.0769 \\
\hline
\end{tabular}

Notes: The critical values for $Z_{t}$ are reported by Hamilton (1994, Table B.6, 763): - 2.58 (10 percent), -2.89 (5 percent), and -3.51 (1 percent). 


\section{EMPIRICAL RESULTS ${ }^{5}$}

As is standard in time series analysis, we start off by studying the univariate characteristics of the data. In this regard, we performed tests of stationarity on our variables $(\ln (m), \ln (r)$ and $r$ using the Phillips and Perron (1988) test, reported in Table 1. The table reports values for the intercept $(\hat{\mu})$ and slope coefficients $(\hat{\rho})$ from an ordinary least squares regression of each variable on a constant and its own lagged value, along with $Z_{t}$ - the Phillips and Perron (1988) test statistic, which corrects the conventional $t$-statistic for testing the null hypothesis of a unit root, i.e., $\rho=1$, for serial correlation in the regression error using the Newey and West (1987) estimator of the error variance. $Z_{t}$ values are reported for the lag truncation parameter, $q$, ranging between 0 and 8 . Note that, $q$ defines the bound on the number of sample autocovariances used in computing the Newey and West (1987) estimate Based on the critical values for $Z_{t}$ reported in Table B.6 of Hamilton (1994, 763) under the heading "Case 2", none of these test statistics allows the null hypothesis of a unit root to be rejected. The result thus, paves the way for the tests of cointegration, which we carry out below, between $\ln (m)$ and $\ln (r)$ in (1) and $\ln (m)$ and $r$ in (2).

The Phillips and Ouliaris (1990) test for cointegration first uses ordinary least squares to estimate the intercept and slope coefficient in linear relationships, as in equations (1) or (2), between two non-stationary variables, and then applies the Phillips and Perron (1988) test to determine whether the regression error from the equation is stationary or nonstationary. If the null hypothesis of a unit root in the error can be rejected, then either (1) or (2) is believed to represent a cointegrating relationship. In Table 2, we present the results from the Phillips and Ouliaris (1990) tests, which includes the estimate of the intercepts $(\hat{\alpha})$ and slope coefficients $(\hat{\beta})$ from equations (1) and (2), the slope coefficient ( $\hat{\rho}$ ) from a regression of the error term from (1) or (2) on its own lagged value, but without a constant, and the Phillips and Ouliaris (1990) $Z_{t}$ statistic for values of the Newey and West (1987) lag truncation parameter (q) ranging again between 0 and 8 . Based on the critical values for the $Z_{t}$ statistic obtained from Table B.9 in Hamilton $(1994,766)$ under the heading "Case 2", the null hypothesis of no cointegration between $\ln (\mathrm{m})$ and $\ln (\mathrm{r})$ cannot be rejected by all the tests reported in the top panel of Table 2. However, barring one at $q=0$, all of the remaining tests in Table 2's bottom panel reject their null of no cointegration between $\ln (\mathrm{m})$ and $r$ at either the 90 or 95 percent confidence levels. So, the results tend to suggest a semi-log form of long-run money demand relationship over the period of 1980Q1-2010Q4. To test for the robustness of the results on cointegration obtained in Table 2, Table A1 in the appendix, reports the results from Johansen's (1991) test for cointegration applied to equations (1) and (2). As with the Phillips and Ouliaris (1990) test, results point to the semi-log specification as providing a better description of long-run relationship between $m$ and $r$ for our sample.

${ }^{5}$ To ensure consistency, all the computations, barring the PPR method, have been done using the codes written by Prof. Peter N. Ireland for his paper: On the Welfare Cost of Inflation and the Recent Behavior of Money Demand, which appeared in the June 2009 issue of the American Economic Review. The codes are available for download on his website: https://www2.bc.edu/peter-ireland/programs.html. For the PPR method, we relied on the "ppr" package in R. 
Table 2- Phillips-Ouliaris Cointegration Test Results

\begin{tabular}{|c|c|c|c|c|c|}
\hline \multirow[t]{10}{*}{$\ln (\mathrm{m})=\alpha-\beta \ln (\mathrm{r})$} & $\hat{\alpha}$ & $\hat{\beta}$ & $\hat{\rho}$ & $q$ & $Z_{t}$ \\
\hline & -2.0374 & -0.0477 & 0.9509 & 0 & -1.7379 \\
\hline & & & & 1 & -1.8938 \\
\hline & & & & 2 & -2.0395 \\
\hline & & & & 3 & -2.1824 \\
\hline & & & & 4 & -2.2929 \\
\hline & & & & 5 & -2.3644 \\
\hline & & & & 6 & -2.4343 \\
\hline & & & & 7 & -2.4727 \\
\hline & & & & 8 & -2.4836 \\
\hline \multirow[t]{10}{*}{$\ln (m)=\alpha-\beta r$} & $\hat{\alpha}$ & $\hat{\beta}$ & $\hat{\rho}$ & $\mathrm{q}$ & $\mathrm{Z}_{\mathrm{t}}$ \\
\hline & -1.7904 & -1.7027 & 0.8773 & 0 & -2.9231 \\
\hline & & & & 1 & $-3.1524^{*}$ \\
\hline & & & & 2 & $-3.2199 *$ \\
\hline & & & & 3 & $-3.3509 *$ \\
\hline & & & & 4 & $-3.3772^{* *}$ \\
\hline & & & & 5 & $-3.4172^{* *}$ \\
\hline & & & & 6 & $-3.478^{* *}$ \\
\hline & & & & 7 & $-3.4658^{* *}$ \\
\hline & & & & 8 & $-3.4407 * *$ \\
\hline
\end{tabular}

Notes: The critical values for $Z_{t}$ are reported by Hamilton (1994, Table B.9, 766): - 3.07 (10 percent), -3.37 (5 percent), and -3.96 ( 1 percent). Hence $*$ and $* *$ indicate that the null hypothesis of no cointegration can be rejected at the 90 and 95 percent confidence levels.

Recall that in equations (1) and (2), we impose a unitary income elasticity of money demand. As a matter of additional robustness check, in Table 3, we repeated the Phillips and Ouliaris (1990) tests to the more flexible specification that links the log of real money balances $(\ln (M / P))$ to the $\log$ of real GDP $(\ln (Y / P))$ and the $\log$ of the nominal interest rate $(\ln (r))$. In other words, as in Ireland (2009), we wanted to ensure that failure of the Phillips and Ouliaris (1990) tests, carried out in Table 2 , to reject the null hypothesis of no cointegration between $\ln (m)$ and $\ln (r)$ does not results from the imposition of the so-called constraint of unitary income elasticity. The table shows the ordinary least squares estimates of the intercept $(\hat{\alpha})$ together with the slope coefficients measuring the income ealsticity $\left(\hat{\beta}_{\mathrm{y}}\right)$ and interest elasticity $\left(\hat{\beta}_{\mathrm{r}}\right)$ of money demand. As before, the table shows values of the Phillips and Ouliaris (1990) $Z_{t}$ statistic for values of the Newey and West (1987) lag truncation parameter $q$ ranging between 0 and 8 . As can be seen from Table 3, the point estimate of the income elasticity of money demand $\left(\hat{\beta}_{\mathrm{y}}\right)=1.0921$ exceeds unity, causing the estimate of the interest elasticity of money demand $\left(\hat{\beta}_{\mathrm{r}}\right)$ to decline to 0.032 , when compared to the case shown in Table 2 , where we had imposed unitary income elasticity. But, more importantly, as in Table 2, based on the critical values of the $Z_{t}$ statistic reported under the heading "Case 3" in Table B.9 of Hamilton (1994, 
766), none of the Phillips and Ouliaris (1990) tests could again rejects the null hypothesis of no cointegration between $\ln (m)$ and $\ln (r)$, suggesting that the lack of cointegration between these two variables of concern, do not stem from the assumption of unitary income elasticity of money demand.

Table 3- Phillips-Ouliaris Cointegration Test Results

\begin{tabular}{|c|c|c|c|c|c|c|}
\hline \multirow[t]{9}{*}{$\ln (\mathrm{M} / \mathrm{P})=\alpha+\beta_{\mathrm{y}} \ln (\mathrm{Y} / \mathrm{P})-\beta_{\mathrm{r}} \ln (\mathrm{r})$} & $\hat{\alpha}$ & $\hat{\beta}_{\mathrm{y}}$ & $\hat{\beta}_{\mathrm{r}}$ & $\hat{\rho}$ & q & $\mathrm{Z}_{\mathrm{t}}$ \\
\hline & -2.8265 & & & & $\begin{array}{l}0 \\
1\end{array}$ & $\begin{array}{l}-1.9178 \\
-2.2033\end{array}$ \\
\hline & & & & & 2 & -2.4241 \\
\hline & & & & & 3 & -2.6049 \\
\hline & & & & & 4 & -2.7161 \\
\hline & & & & & 5 & -2.7873 \\
\hline & & & & & 6 & -2.8503 \\
\hline & & & & & 7 & -2.8779 \\
\hline & & & & & 8 & -2.8729 \\
\hline
\end{tabular}

Notes: The critical values for $Z_{t}$ are reported by Hamilton (1994, Table B.9, 766): - 3.52 (10 percent), -3.80 (5 percent), and -4.36 (1 percent).

In Table 4, we present the "dynamic OLS" (DOLS) estimates of the parameters of the semi$\log$ cointegrating relationship. Each of the parameter estimates, reported in Table 4, is obtained from an ordinary least squares regression of $\ln (m)$ on a constant, the level of the nominal interest rate $(r)$, and $p$ leads and lags of the quarter-to-quarter change in the nominal interest rate $(\Delta r)$. Note, unlike the static Phillips and Ouliaris (1990) tests, the DOLS cannot be used to test the hypotheses of cointegration or no cointegration, so the DOLS assumes that the non-stationary variables, namely, $\ln (m)$ and $r$ are cointegrated. But, under the assumption of cointegration, the DOLS estimates have been shown to be asymptotically efficient and asymptotically equivalent to the ML estimates of Johansen (1991). ${ }^{6}$ Further, as pointed out by Ireland (2009), it is possible to draw familiar comparisons between the parameter estimates and their standard errors, since traditional Wald test statistics formed from these DOLS estimates have conventional normal or chi-squared asymptotic distributions. Though adding leads and lags of $\Delta r$ to the estimated equations controls for possible correlation between the interest rate $r$ and the residual from the semi-log cointegrating relationship, any serial correlation that remains in the error term from the DOLS equation should still be accounted for when obtaining the standard errors for the DOLS estimates by using the using Newey and West (1987) estimator of the regression error variance for various values of the lag truncation parameter $q$. In Table 4, we report the DOLS estimates of the intercept $(\hat{\alpha})$ and the slope coefficient $(\hat{\beta})$ from the semi-log cointegrating relationship between $m$ and $r$, together with standard errors (s.e. $(\hat{\beta}))$ for the long-run interest semi-elasticity of money demand.

\footnotetext{
${ }^{6}$ Refer to Stock and Watson (1993) for further details.
} 
In general, the DOLS estimates from Table 4, though slightly higher (lower) in absolute value for the interest semi-elasticity (regression constant) in majority of the cases, are quite similar to those obtained under the static Phillips and Ouliaris (1990) tests in Table 2. In addition, a conventional comparison between a point estimate and its standard error can be made for each value of the number of leads and lags of $\Delta r$ (i.e., $p$ ) included in the DOLS regressions, and for each value of the number of regression-error autocorrelations $(q)$ allowed for in the Newey and West (1987) variance estimator. With the $t$-statistic $(=\hat{\beta} /$ s.e. $(\hat{\beta}))$ having the usual, normal asymptotic distribution, and the standard errors around the point estimates of 1.7 and 1.8 being quite small, the results confirm that the estimated interest semi-elasticity of money demand differs significantly from zero.

Table 4 - Dynamic OLS Estimates

\begin{tabular}{|c|c|c|c|c|c|}
\hline $\ln (m)=\alpha-\beta r$ & $\hat{\alpha}$ & $\hat{\beta}$ & s.e. $(\hat{\beta})$ & $\mathrm{p}$ & $q$ \\
\hline & -1.7831 & -1.7951 & 0.1216 & 1 & 2 \\
\hline & & & 0.1456 & & 4 \\
\hline & & & 0.1584 & & 6 \\
\hline & & & 0.1638 & & 8 \\
\hline & -1.7829 & -1.7768 & 0.1284 & 2 & 2 \\
\hline & & & 0.1536 & & 4 \\
\hline & & & 0.1663 & & 6 \\
\hline & & & 0.1715 & & 8 \\
\hline & -1.7850 & -1.7186 & 0.1389 & 3 & 2 \\
\hline & & & 0.1654 & & 4 \\
\hline & & & 0.1789 & & 6 \\
\hline & & & 0.1849 & & 8 \\
\hline & -1.7854 & -1.6835 & 0.1361 & 4 & 2 \\
\hline & & & 0.1597 & & 4 \\
\hline & & & 0.1721 & & 6 \\
\hline & & & 0.1786 & & 8 \\
\hline
\end{tabular}

Notes: $p$ defines the leads and lags on $\Delta r$ in the dynamic ordinary least squares regression which involves $\ln (m)$, a constant, and $r$.

Having found robust cointegrating relationship between the $\ln (m)$ and $r$, Table 5 now reports the DOLS estimates of the semi-log specification by relaxing the assumption of a unitary income elasticity of money demand. The table reports point estimates $\hat{\alpha}, \hat{\beta}_{\mathrm{y}}$, and $\hat{\beta}_{\mathrm{r}}$ of the intercept $(\hat{\alpha})$ and slope coefficients $\left(\hat{\beta}_{\mathrm{y}}\right.$ and $\left.\hat{\beta}_{\mathrm{r}}\right)$ from the cointegrating relationship between $\ln (M / P)$ with $\ln (Y / P)$ and $r$, when $p$ leads and lags of $\Delta \ln (\mathrm{Y} / \mathrm{P})$ and $\Delta \mathrm{r}$ are also included in the otherwise static regression. Further, Table 5 also includes the standard errors, s.e. $\left(\hat{\beta}_{\mathrm{y}}\right)$ and s.e. $\left(\hat{\beta}_{\mathrm{r}}\right)$, for $\hat{\beta}_{\mathrm{y}}$ and $\hat{\beta}_{\mathrm{r}}$, which, in turn, are corrected for serial correlation using the Newey and West (1987) estimator of the regression error variance for various values of the lag truncation parameter $q$. 
Table 5 - Dynamic OLS Estimates

\begin{tabular}{|c|c|c|c|c|c|c|c|c|}
\hline $\ln (\mathrm{M} / \mathrm{P})=\alpha+\beta_{\mathrm{y}} \ln (\mathrm{Y} / \mathrm{P})-\beta_{\mathrm{r}} \mathrm{r}$ & $\hat{\alpha}$ & $\hat{\beta}_{\mathrm{y}}$ & s.e. $\left(\hat{\beta}_{\mathrm{y}}\right)$ & $\hat{\beta}_{\mathrm{r}}$ & s.e. $\left(\hat{\beta}_{\mathrm{r}}\right)$ & $\mathrm{p}$ & q & $\mathrm{W}\left(\beta_{\mathrm{y}}=1\right)$ \\
\hline & -1.7086 & 0.9927 & 0.0273 & -1.8349 & 0.2212 & 1 & 2 & 0.072 \\
\hline & & & 0.0328 & & 0.2654 & & 4 & 0.05 \\
\hline & & & 0.0359 & & 0.2903 & & 6 & 0.0418 \\
\hline & & & 0.0373 & & 0.302 & & 8 & 0.0386 \\
\hline & -1.6601 & 0.9878 & 0.0267 & -1.8259 & 0.2302 & 2 & 2 & 0.2082 \\
\hline & & & 0.032 & & 0.2756 & & 4 & 0.1452 \\
\hline & & & 0.035 & & 0.3013 & & 6 & 0.1215 \\
\hline & & & 0.0366 & & 0.3153 & & 8 & 0.1109 \\
\hline & -1.677 & 0.9896 & 0.028 & -1.7524 & 0.2658 & 3 & 2 & 0.137 \\
\hline & & & 0.0337 & & 0.319 & & 4 & 0.0951 \\
\hline & & & 0.0369 & & 0.3503 & & 6 & 0.0789 \\
\hline & & & 0.0389 & & 0.3691 & & 8 & 0.071 \\
\hline & -1.7332 & 0.9955 & 0.0272 & -1.7233 & 0.2702 & 4 & 2 & 0.0277 \\
\hline & & & 0.0321 & & 0.3196 & & 4 & 0.0198 \\
\hline & & & 0.0352 & & 0.3502 & & 6 & 0.0165 \\
\hline & & & 0.0372 & & 0.3703 & & 8 & 0.0148 \\
\hline
\end{tabular}

Notes: The critical value for $\mathrm{W}\left(\beta_{\mathrm{y}}=1\right)$ are reported by Hamilton (1994, Table B.2, 754): 2.71 (10 percent), 3.84 (5 percent), and 6.63 (1 percent).

Finally, the table, presents the corresponding Wald $(F)$ statistics for testing the null hypothesis of a unitary income elasticity of money demand imposed to obtain DOLS estimation results in Table 4. The point estimates of the income elasticity in Table 5 are estimated to be slightly lower than one. However, none of the Wald tests fail to reject the null hypothesis of an income elasticity of one. Further, the interest semi-elasticity, though slightly smaller in absolute value when compared to their corresponding values in Table 4 , comparing $\hat{\beta}_{\mathrm{r}}$ and s.e. $\left(\hat{\beta}_{\mathrm{r}}\right)$ suggest that the estimates of the interest semi-elasticity are again significantly different from zero. Taken together, all these results tend to suggest that the semi-log specification with an unitary income elasticity of money demand, as 
outlined in equation (2), provides the best description of long-run money demand relationship in our data sample covering 1980Q1-2010Q4. At this stage, it is important to point out that our estimates discussed in Tables 1 through 5 are qualitatively and also quantitatively quite similar to those obtained by Ireland (2009). This is understandable since the four years (16 quarters) of additional data is not enough information to produce significant changes in the estimates. The reader is referred to the corresponding Tables 1 through 5 in Ireland (2009) for further details and making comparisons.

Next, we turn our attention to a nonparametric estimation of the semi-log model used under the DOLS approach, based on the PPR method, details of which can be found in Friedman and Stuetzle (1981) and Vinod (1998). We have, however, provided the basics of the PPR method in the Appendix of this paper. As indicated earlier, though Vinod (1998) applied this methodology to estimate a non-linear long-run money demand relationship for the US economy using annual data covering the period of 1900-1989, we go a step further by recovering the welfare cost estimates obtained from this non-linear long-run semi-log money demand function. In this regard, we estimate the following model:

$$
\ln (m)=\alpha+\sum_{i=1}^{m_{1}} \gamma_{i} f_{i}\left(\beta^{\prime} X\right)+\eta
$$

where, $\alpha$ is the overall mean for the response variable $(\ln (m)), f_{i}($.$) denote the unknown ridge function$ corresponding to the $i$-th chosen direction, which is estimated from the data, $\eta$ are mean zero errors, with unchanged variance over the entire data set, $\gamma_{i}$ is the coefficient corresponding to $i$-th projection directions, $\beta_{i}$ is the $i$-th projection direction vectors corresponding to the multivariate regressor vector $X$ (which includes $r$ and $p=4$ leads and lags of $\Delta r$ ), so that $\left\{\beta_{i}\right\}_{i=1}^{m_{1}}$ are orthonormal. $\gamma_{i}$ and $\beta_{i}$ are estimated from the data, using the projection pursuit regression method. Here each response was given equal weight for estimating the aforementioned parameters and functions. We use the cubic splines method instead of the super smoother and GCV splines methods, ${ }^{7}$ simply because it yields smaller values of sum of residual autocorrelations when fitting the model. Note the model has 9 regressors, and hence to avoid the curse of dimensionality, we choose the number of directions $m_{1}$ so that it yields the least sum of residual autocorrelations, which, in turn yielded $m_{1}=9$. The $p$-value corresponding to the goodness of model fit was found to be very close to 1 . Note, the decision to use $p=4$, emanated from the fact that the sum of squared error (SSE) for the DOLS models reported in Table 4, was lowest under the case with $p=4$, relative to $p=1,2$ and 3 . This though, is expected since the DOLS with $p=4$ nests the other three cases. However, the Akaike Information Criterion (AIC) was found to be the smallest for $p=4$ relative to the other three cases. ${ }^{8}$ In light of this, we decided to estimate the PPR with $p=4$.

For the sake of comparison of the long-run semi-elasticity of the interest rate obtained from the linear models, in Table 6, we present, besides the intercept estimated term, the estimated

\footnotetext{
${ }^{7}$ Results from the super smoother and GCV splines methods are available upon request from the authors.

8 The values for the AIC were: $-4.1539,-4.1491,-4.3334$ and -4.4009 for $p=1,2,3$ and 4 respectively. Further, analysis of variance (ANOVA) also ensured that the SSE for $p=4$ was significantly smaller compared to the cases of $p=1,2$ and 3. Details of ANOVA analysis are available upon request from the authors.
} 
derivative of $\ln (m)$ with respect to $r$ at the average value of $r(\bar{r})$, and all the leads and lags of $\Delta r$ terms set to zero from the PPR, which essentially provides a comparable measure of the long-run interest rate semi-elasticity in the non-linear case. ${ }^{9}$ We also examined the correlation of the real and the estimated responses, which was found to be 0.99. We used the bootstrapping methods developed by Efron and Tibshirani (1993) and replicated the PPR 1000 times. Let us denote s.d. = standard deviation of the bootstrap samples corresponding to the semi-elasticity, and let "95\% Bootstrap BCa C.I" denote the 95 percent bootstrap bias-corrected confidence intervals. ${ }^{10}$ Based on our PPR analysis, we find that the interest rate semi-elasticity is -3.6453 , which is significant, but with a pretty wide 95 percent confidence interval of $(-4.3650,-2.5570)$, and a relatively large s.d. of 1.0751. Note, the obtained semi-elasticity is more than double when compared to those obtained under the linear models. As a matter of further comparison, in Table 6, we also report the bootstrap estimates for the intercept and the semi-elasticity of the interest rate along with its 95 percent confidence interval, obtained from the linear DOLS model discussed above with $p=4 .{ }^{11}$ The interest semi-elasticity is found to be 1.7460 (absolute value), which is comparable to those obtained in Table 4, but again as in the other linear cases, the estimate is more than half of what is obtained under the PPR method. Note compared to the PPR case, the 95 percent confidence interval ($2.0167,-1.4901)$ is quite tight around the semi-elasticity of the interest rate and the estimate also has a way smaller s.d. (= 0.1362). But, as far as the bigger standard deviation is concerned, the result is quite expected, since it is one of the drawbacks of the PPR method. The reader is referred to Vinod (1998) for further details regarding the advantages and drawbacks of the PPR method.

Though, the standard deviation of the estimate is larger in the PPR case, when we evaluated the SSEs for the bootstrapped DOLS model and the PPR, the latter was found to fit the data way better at the $\min \left(=\right.$ minimum), $\max$ (= maximum), $Q_{1}$ (= first quartile), Median (= median), Mean (= mean), $Q_{3}$ (= third quartile) of the bootstrap samples. The following are the bootstrap estimates of the SSE from the PPR (DOLS) at the min, $Q_{1}$, Median, Mean, $Q_{3}$, max, respectively: 0.0048 (0.0264); 0.0099 (0.0487); 0.0115 (0.0572); 0.0117 (0.0575); 0.0135 (0.0660); 0.0232 (0.0940). ${ }^{12}$ Clearly, given that the inherent variation in the data is captured better by the PPR model, the estimates from this

${ }^{9}$ The semi-elasticity: $S E=\left.\frac{d \ln (m(r))}{d r}\right|_{r=r_{0}}=\lim _{\varepsilon \rightarrow 0^{+}} \frac{\ln \left(m\left(r_{0}+\varepsilon\right)-\ln \left(m\left(r_{0}\right)\right)\right)}{\varepsilon}$ is estimated using a finite difference, that is, $\frac{\ln \left(m\left(r_{0}+\varepsilon_{0}\right)-\ln \left(m\left(r_{0}\right)\right)\right)}{\varepsilon_{0}}$ (or $\left.\frac{\ln \left(m\left(r_{0}+\varepsilon_{0}\right)+\ln \left(m\left(r_{0}\right)\right)\right)}{\varepsilon_{0}}\right)$, whichever appropriate) with $\varepsilon_{0}=10^{-5}$, which is small enough to ensure that the finite difference is close to the derivative. Note, $r_{0}$ denotes the point where the derivative is to be computed...

10 The full set of estimated parameters of the model, which includes the projection direction vectors and ridge coefficients have been suppressed here to save space. They are, however, available upon request from the authors, as are the results of the PPR model with $p=1,2$ and 3. For these three cases, the SE was not found to be significant with wide confidence bands. However, the estimated welfare costs, as reported below in Table 7, were virtually the same.

11 As with results reported in Table 4, the SSE was lowest with $p=4$ for the bootstrapped DOLS, and again, as before the AIC was lowest for this case, and the ANOVA indicated that the SSE for $p=4$ was significantly lower than with $p=$ 1,2 and 3. Details of ANOVA analysis are available upon request from the authors. In addition, the full-set of results for $p=1,2$ and 3 are also available upon request from the authors. As in Table 4, the results for the bootstrapped DOLS for values of $p$ ranging between 1 and 4 were very similar, and, understandably, so were the welfare cost estimates.

12 The PPR method was found to produce lower SSEs in comparison to the bootstrapped DOLS for the cases of $p=1$, 2 and 3 as well. 
method is expected to be more accurate, with the uncertainty in the data reflected in the wider confidence bands and large standard errors. In addition to the semi-log cointegrating relationships obtained in Table 2 and for $p=4$ in Table 4, in Figure 3, we superimpose the cointegrating relationship between $\ln (m)$ and $r$ and the semi-log long-run money demand relationship obtained based on the bootstrapped DOLS model on the scatter plot of $m$ and $r$. Note, the plotted non-linear long-run relationship corresponds to the non-linear functional form obtained by setting the leads and lags of $\Delta r$ to zero. As is evident, the long-run semi-log money demand relationship obtained with the PPR model tracks the data much better, in terms of data coverage, than its linear counterparts, which are virtually indistinguishable from each other. However, as with the linear models, the non-linear long-run money demand function too fails in capturing the recent moneyinterest relationship under virtually zero nominal interest rates. Interestingly, in an attempt to cover more data points the non-linear money demand function indicates a positive relationship between the money-income ratio and the nominal interest rate at the high-end of the latter, which, in turn, prevailed during the early section of the sample.

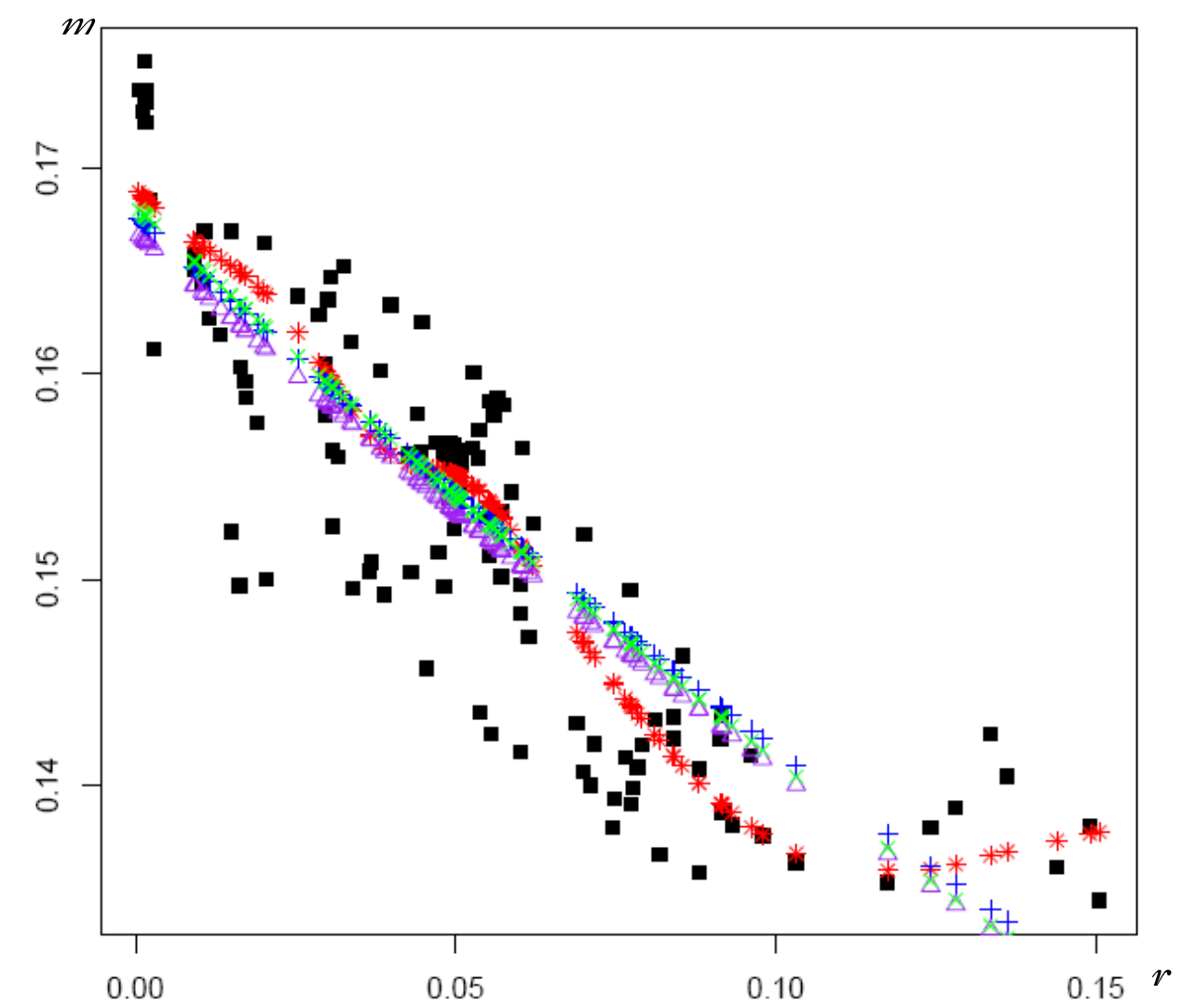

Figure 3. Cointegrating Relationships between $\ln (m)$ and $r$ (1980Q1-2010Q4): Original Data [Black solid square signs]; $\ln (m)=-1.7904-1.7027^{*} r$ [Purple triangle signs with an angle facing upward]; $\ln (m)=-1.7854-1.6835^{*} r$ [Blue plus signs]; Long-run semi-log money demand function based on PPR [Red star signs]; $\ln (m)=-1.7830-1.7460^{*} r$ [Green cross signs]. 
Table 6 - Projection Pursuit Regression and Bootstrapped DOLS Results

\begin{tabular}{lccccc}
\hline \hline & $\hat{\alpha}$ & $95 \% \mathrm{BCa} C \mathrm{CI}(\hat{\alpha})$ & $S E$ & $95 \% \mathrm{BCa} \mathrm{CI}($ S.E. $)$ & s.d.(S.E.) \\
PPR & -1.7761 & $(-1.7953,-1.7699)$ & -3.6453 & $(-4.3650,-2.5570)$ & 1.0751 \\
Bootstrapped DOLS & -1.7830 & $(-1.7950,-1.7700)$ & -1.7460 & $(-2.0167,-1.4901)$ & 0.1362 \\
\hline
\end{tabular}

Notes: The semi-elasticity: $S E=\left.\frac{d \ln (m(r))}{d r}\right|_{r=r_{0}}=\lim _{\varepsilon \rightarrow 0^{+}} \frac{\ln \left(m\left(r_{0}+\varepsilon\right)-\ln \left(m\left(r_{0}\right)\right)\right)}{\varepsilon}$ is estimated using a finite difference, that is, $\frac{\ln \left(m\left(r_{0}+\varepsilon_{0}\right)-\ln \left(m\left(r_{0}\right)\right)\right)}{\varepsilon_{0}}$ (or $\left.\frac{\ln \left(m\left(r_{0}+\varepsilon_{0}\right)+\ln \left(m\left(r_{0}\right)\right)\right)}{\varepsilon_{0}}\right)$, whichever appropriate) with $\varepsilon_{0}=10^{-5}$, which is small enough to ensure that the finite difference is close to the derivative. Note, $r_{0}$ denotes the point where the derivative is to be computed.For the bootstrapped DOLS: $S E=\hat{\beta}$. Here $p=4$ for both the bootstrapped DOLS and the PPR.

Finally, in Table 7 we present the estimates of the welfare cost of inflation implied by equation (5) based on the linear regression results in Tables 2, 4 and 6, and by equation (6) for the non-linear case. Recall, for the non-linear case, the welfare cost formula does not have a closedform, and, hence, needs to be obtained through Monte Carlo integration of the long-run non-linear money demand function. ${ }^{13}$ Since, the static and dynamic OLS estimates, as well as, the bootstrapped DOLS estimates look quite similar, so do the implied welfare costs. Assuming, as in Lucas (2000) and Ireland (2009), that the steady-state real interest rate equals 3 percent, so that $r=0.03$ corresponds to zero inflation, $r=0.05$ corresponds to 2 percent annual inflation, and $r=0.13$ corresponds to 10 percent annual inflation, the regression coefficients for the linear cases yield the welfare cost of pursuing a policy of price stability as opposed to the Friedman (1969) rule at less than 0.015 percent of income, the cost of 2 percent inflation at less than 0.04 percent of income, and the cost of 10 percent inflation at less than 0.25 percent of income. ${ }^{14}$ These welfare cost estimates are similar to those obtained by Ireland (2009), but lie far below those computed by Lucas (2000). Note, we can also obtain the cost of 10 percent inflation compared to price stability using: $w(0.13)-$ $w(0.03)$, which, in turn, lie between 0.19 and 0.21 percent of income, numbers that are still smaller than, but resemble more closely, Fischer's (1981) estimate of 0.30 percent of income, Lucas's (1981) estimate of 0.45 percent of income, and, more recently, Ireland's (2009) estimated range of 0.20 and 0.22 percent of income. In comparison, the welfare cost of inflation obtained from the semi-log non-linear long-run money demand for 0,2 and 10 percent of inflation are as high as 0.49, 0.80 and 1.95 percent of GDP respectively. ${ }^{15}$ The result is expected given the larger data coverage of the non-

\footnotetext{
13 We used a seed equal to 20 to obtain our results for the welfare costs. However, when we checked the robustness of our results based on seeds equal to 30 and 40, the welfare costs only changed at the sixth decimal place. The details of these results are available upon request from the authors. The small standard errors reported in Table 7, and also those obtained under the alternative seeds, also vouch for the robustness of our results.

${ }^{14}$ If we replace the estimated intercept and the interest semi-elasticity obtained from the PPR in equation (5), the welfare costs of inflation for 0,2 and 10 percent of inflation are respectively, 0.0232, 0.0616 and 0.3444 percent of GDP, which, in turn, are relatively higher compared to those obtained under the linear cases.

15 One of the referees suggested that we reevaluate our welfare cost estimates using the trapezoidal method for the numerical integration. Given that, the trapezoid method and Simpson's method are comparable, but the fact that in most cases Simpson's method is faster in terms of convergence (Atkinson, 1989), we used the composite Simpson's method of numerical integration instead. In this case, the number of points used for integration within each interval was $n=10000$.
} 
Table 7 - Welfare Cost Estimates as Percent of Income

\begin{tabular}{lccc}
\hline \hline & & & \\
Regression & & & \\
& 0.0124 & $w(0.05)$ & $w(0.13)$ \\
Static OLS & {$[0.0009]$} & 0.0336 & 0.2075 \\
& 0.0131 & $0.0025]$ & {$[0.0141]$} \\
Dynamic OLS $(p=1)$ & {$[0.0011]$} & {$[0.0030]$} & 0.2186 \\
& 0.0130 & 0.0352 & $0.0170]$ \\
Dynamic OLS $(p=2)$ & {$[0.0011]$} & {$[0.0030]$} & {$[0.0170]$} \\
& 0.0125 & 0.0340 & 0.2103 \\
Dynamic OLS $(p=3)$ & {$[0.0010]$} & {$[0.0027]$} & {$[0.0151]$} \\
& 0.0122 & 0.0334 & 0.2065 \\
Dynamic OLS $(p=4)$ & {$[0.0010]$} & {$[0.0027]$} & {$[0.0155]$} \\
& 0.0128 & 0.0346 & 0.2135 \\
Bootstrapped DOLS $(p=4)$ & {$[0.0027]$} & {$[0.0045]$} & {$[0.0177]$} \\
& 0.4930 & 0.8036 & 1.9468 \\
PPR $(p=4)$ & {$[0.0049]$} & {$[0.0067]$} & {$[0.0129]$} \\
\hline
\end{tabular}

Notes: The welfare cost calculations assume the steady-state annual real interest rate equals 3 percent (Ireland, 2009). Hence, $r=0.03,0.05$ and 0.13 under price stability, 2 and 10 percent inflation respectively. Welfare Costs for the linear models are obtained from (5) with $\ln (B)=\hat{\alpha}$ and $\xi=\hat{\beta}$ (in absolute value). For the PPR we use Monte Carlo integration. Numbers in [ contain the standard errors for the welfare cost estimates obtained using 1000 bootstrap replications.

linear long-run money demand relationship, as depicted in Figure 3. Interestingly, these figures are even higher than the dynamic general equilibrium estimates provided by Dotsey and Ireland (1996) and Lucas (2000). Lucas' (2000) corresponding estimates for 0, 2 and 10 percent of inflation for the semi-log case are $0.10,0.25$ and 1.17 percent of GDP respectively ${ }^{16}$, while, Dotsey and Ireland (1996) indicates that the welfare cost of inflation for a range of 4 to 10 percent of inflation would be around 0.27 to 1.73 percent of GDP. Note, the cost of 10 percent inflation relative to price stability too is way higher at 1.46 percent of GDP, when compared to at most 0.21 percent of GDP in the linear case. Given such stark differences in the estimates of the welfare costs between the linear and nonlinear money demand functions, it is important to analyze the precision of the welfare cost estimates obtained under these two cases. In light of this, in Table 7, we also report the corresponding standard errors for the welfare cost estimates from the static OLS, the different DOLS and the PPR models, obtained based on 1,000 bootstrap replications. As can be seen from the standard errors, they are quite similar across the static OLS model and the different DOLS models, barring the bootstrapped DOLS, which produces consistently higher standard errors. The

For this case, the welfare cost of inflation (standard errors) obtained from the semi-log non-linear long-run money demand for 0, 2 and 10 percent of inflation were found to be 0.52 (0.01), 0.88 (0.02) and 2.35 (0.05) percent of GDP respectively, i.e., they were even higher compared to those obtained under the Monte Carlo integration, but also has higher standard errors.

${ }^{16}$ For Lucas' (2000) preferred log-log case 0 and 2 percent rates of inflation produced welfare losses of 0.85 and 1.09 percent of GDP, which are bigger relative to what our PPR method yields. However, at the 10 percent level Lucas (2000) obtains a welfare cost of 1.76 percent of GDP- a values less than what we obtain at the same level of inflation. 
static OLS produces the lowest standard errors amongst these models for the three different rates of inflation namely, under price stability, 2 and 10 percent considered here. Interestingly, all the different DOLS models and the static OLS model produces lower standard errors in comparison to the PPR method for the case of price stability and the 2 percent rate of inflation. However, the PPR, has a lower standard error relative to all the models for the 10 percent rate of inflation; indicating that the PPR produces more precise estimates of the welfare cost for higher rates of inflation, while the static OLS tends to do the same for lower levels of the inflation rate. This result is not surprising, once we look at the data coverage of these models in Figure 3. The PPR tracks the data way better than the linear models at higher rates of inflation, and hence understandably, produces more precise estimates of the welfare cost of inflation.

\section{CONCLUSIONS}

This paper, first, estimates the appropriate, log-log or semi-log, linear long-run money demand relationship capturing the behavior US money demand over the period of 1980:Q1 to 2010:Q4, using the standard linear cointegration procedures found in the literature (Phillips and Ouliaris, 1990; Johansen, 1991; and Stock and Watson, 1993), and the corresponding nonparametric version of the same based on PPR methods outlined in Friedman and Stuetzle (1981). We then, compare the resulting welfare costs of inflation obtained from the linear and nonlinear money demand cointegrating equations. We make the following observations: (i) The null of unitary long-run income elasticity of money cannot be rejected; (ii) Money demand functions can, thus, be expressed as capturing relationships between the nominal money-income ratio and the nominal interest rate; (iii) Though, the logarithm of the money-income ratio, the logarithm of the nominal interest rate and the nominal interest rate are all integrated of order one, the appropriate money demand relationship for the period of 1980:Q1 to 2010:Q4 is captured by a semi-log function, since no cointegrating relationship could be obtained between the logarithm of the nominal money-income ratio and the nominal interest rate; (iv) The interest semi-elasticity obtained from the PPR method is found to be at 3.6453 (in absolute value), which was more than double the highest possible corresponding value (1.7951) obtained under various linear cases; (v) Based on the estimation of semi-log cointegrating equations, the welfare cost of inflation was found to at the most lie between 0.0131 percent of GDP to 0.2186 percent of GDP for inflation rates between 0 percent and 10 percent, mimicking comparable welfare estimates obtained for the US by Fischer (1981), Lucas (1985) and Ireland (2009); (vi) In comparison, the welfare cost of inflation obtained from the semi-log non-linear longrun money demand function, obtained using the PPR method, for 0 to 10 percent of inflation ranges between 0.4930 to 1.9468 percent of GDP. The result is not surprising given the larger data coverage, in comparison to the linear semi-log models, of the non-linear long-run money demand relationship, though just like the linear semi-log model, the non-linear model too fails to account for the recent high money demand under virtually zero nominal interest rates; (vii) These welfare cost figures, obtained from the PPR method, are even higher than the dynamic general equilibrium estimates provided by Dotsey and Ireland (1996) and Lucas (2000); (viii) Standard errors of the welfare cost estimates obtained from the PPR relative to the linear money demand functions, however, tend to indicate that the nonlinear money demand provides more precise estimates of the welfare costs primarily for higher rates of inflation; (ix) Thus, based on the precision of our findings, perhaps, one would need to rely on the welfare cost estimates obtained from the linear money demand models at lower rates of inflation, but on the nonlinear model at higher levels of inflation, and finally; (x) If we are to believe these high welfare cost estimates obtained from the non-linear 
long-run money demand relationship, then the optimal monetary policy seems to be the Friedman (1969) rule (a deflation that makes the nominal rate equal to zero), but primarily at higher rates of inflation. In other words, the Federal Reserve's current policy, which generates low but still positive rates of inflation, provides an adequate approximation in welfare terms.

\section{REFERENCES:}

Atkinson, Kendall E. 1989. An Introduction to Numerical Analysis. Second Edition. John Wiley \& Sons.

Bailey, Martin J. 1956. “The Welfare Cost of Inflationary Finance.” Journal of Political Economy, 64(2): 93-110.

Cagan, Phillip. 1956. “The Monetary Dynamics of Hyperinflation.” In Studies in the Quantity Theory of Money, ed. Milton Friedman, 25-117. Chicago: University of Chicago Press.

Cynamon, Barry Z., Donald H. Dutkowsky, and Barry E. Jones. 2006. "Redefining the Monetary Aggregates: A Clean Sweep.” Eastern Economic Journal, 32(4): 661-72.

Dotsey, Michael, and Peter N. Ireland. 1996. "The Welfare Cost of Inflation in General Equilibrium." Journal of Monetary Economics, 37(1): 29-47.

Efron, Bradley, and Robert Tibshirani. 1993. An Introduction to the Bootstrap: New York: Chapman and Hall.

Fischer, Stanley. 1981. "Towards an Understanding of the Costs of Inflation: II.” Carnegie-Rochester Conference Series on Public Policy, 15: 5-41.

Friedman, Milton. 1969. "The Optimum Quantity of Money.” In The Optimum Quantity of Money and Other Essays, 1-50. Chicago: Aldine Publishing Company.

Friedman, Jerome H., and Werner Stuetzle. 1981. "Projection Pursuit Regression". Journal of the American Statistical Association, 76(376): 817-823.

Hamilton, James D. 1994. Time Series Analysis. Princeton: Princeton University Press.

Ireland, Peter, N. 2009. "On the Welfare Cost of Inflation and the Recent Behavior of Money Demand.” American Economic Review, 99(3), 1040-1052.

Johansen, Soren. "Estimation and Hypothesis Testing of Cointegration Vectors in Gaussian Vector Autoregressive Models.” Econometrica 59 (November 1991): 1551-1580.

Lucas, Robert E., Jr. 1981. "Discussion Of: Stanley Fischer, 'Towards an Understanding of the Costs of Inflation: II."' Carnegie-Rochester Conference Series on Public Policy, 15: 43-52. 
Lucas, Robert E., Jr. 2000. “Inflation and Welfare.” Econometrica, 68(2): 247-74.

Meltzer, Allan H. 1963. "The Demand for Money: The Evidence from the Time Series." Journal of Political Economy, 71(3): 219-46.

Newey, Whitney K., and Kenneth D. West. 1987. "A Simple, Positive Semi-Definite, Heteroskedasticity and Autocorrelation Consistent Covariance Matrix." Econometrica, 55(3): 703-08.

Phillips, Peter C. B., and S. Ouliaris. 1990. "Asymptotic Properties of Residual Based Tests for Cointegration." Econometrica, 58(1): 165-93.

Phillips, Peter C.B., and Pierre Perron. 1998. "Testing for a Unit Root in Time Series Regression." Biometrika, 75(2): 335-46.

Stock, James H., and Mark W. Watson. 1993. "A Simple Estimator of Cointegrating Vectors in Higher Order Integrated Systems.” Econometrica, 61(4): 783-820.

Vinod, Hrishikesh D. (1998). "Nonparametric Estimation of Non-Linear Money Demand Cointegration Equation by Projection Pursuit Methods". In Computing Science and Statistics, Vol. 30, ed. S. Weisberg, 174-183. Virginia: Interface Foundation, Fairfax Station. 


\section{APPENDIX:}

Table A.1 - Johansen Cointegration Test Results

\begin{tabular}{|c|c|c|c|}
\hline $\ln (m)=\alpha-\beta \ln (r)$ & $p$ & $L R=-\operatorname{Tln}\left(1-\lambda_{1}\right)$ & Cointegrating Vector \\
\hline & 2 & 10.8358 & $26.8289 \ln m_{t}=-55.1082-1.416 \ln r_{t}$ \\
\hline & 3 & 12.3238 & $28.1626 \ln m_{t}=-57.8369-1.4832 \ln r_{t}$ \\
\hline & 4 & 11.8018 & $29.3572 \ln m_{t}=-59.7487-1.3815 \ln r_{t}$ \\
\hline & 5 & $22.8318^{* * *}$ & $26.107 \ln m_{t}=-57.1467-2.4476 \ln r_{t}$ \\
\hline & 6 & $22.2199 * * *$ & $33.5951 \ln m_{t}=-72.5442-2.8478 \ln r_{t}$ \\
\hline & 7 & $14.3963^{*}$ & $39.6133 \ln m_{t}=-82.8366-2.5368 \ln r_{t}$ \\
\hline & 8 & 11.881 & $42.9027 \ln m_{t}=-90.2294-2.9037 \ln r_{t}$ \\
\hline & 9 & 11.2245 & $46.7286 \ln m_{t}=-99.4405-3.5165 \ln r_{t}$ \\
\hline \multirow[t]{9}{*}{$\ln (m)=\alpha-\beta r$} & $p$ & $L R=-\operatorname{Tln}\left(1-\lambda_{1}\right)$ & Cointegrating Vector \\
\hline & 2 & $14.6273^{* *}$ & $33.7746 \ln m_{t}=-59.8913-68.432 r_{t}$ \\
\hline & 3 & $27.3963^{* * *}$ & $36.7019 \ln m_{t}=-65.7979-60.8148 r_{t}$ \\
\hline & 4 & 12.672 & $41.9367 \ln m_{t}=-75.0527-71.9483 r_{t}$ \\
\hline & 5 & $14.9164 * *$ & $35.5027 \ln m_{t}=-64.7156-38.6249 r_{t}$ \\
\hline & 6 & $22.4082^{* * *}$ & $35.7022 \ln m_{t}=-62.55-86.7094 r_{t}$ \\
\hline & 7 & $13.6134^{*}$ & $40.4199 \ln m_{t}=-70.9262-96.0702 r_{t}$ \\
\hline & 8 & $27.8731 * * *$ & $56.0749 \ln m_{t}=-100.198-99.1847 r_{t}$ \\
\hline & 9 & $21.299 * * *$ & $55.5478 \ln m_{t}=-98.275-116.8185 r_{t}$ \\
\hline
\end{tabular}

\section{THE BASICS OF PROJECTION PURSUIT METHOD:}

Projection pursuit regression (PPR) is an extension of additive models, and was developed by 
Freidman and Stuetzle (1981). Like additive models, this model is helpful in reducing the curse of dimensionality in that it uses univariate regression functions, and not multivariate regression functions. Thus the estimation becomes much faster in terms of computation. But this model is different from additive models in that it first projects the data matrix of explanatory variables (usually denoted by $X$ ) in the optimal direction before applying smoothing functions to these explanatory variables.

The model consists of linear combinations of non-linear transformations of linear combinations of explanatory variables. The basic model takes the form

$$
Y=\beta_{0}+\sum_{j=1}^{m_{1}} \gamma_{j} f_{j}\left(\beta_{j}^{\prime} x\right)+\eta
$$

where $x$ is a column vector containing a particular row of the design matrix $X$ which contains $p$ explanatory variables (columns) and $n$ observations (row). Here $Y$ is the a particular observation variable (identifying the row being considered) to be predicted, $\beta_{0}$ here is refers to the ridge coefficient, which is the usual intercept term in a usual regression function. $\gamma_{j}$ is the coefficient corresponding to $j$-th projection directions, $\left\{\beta_{j}\right\}$ is a collection of $r$ vectors (each a unit vector of length $p$, since they are the projection vectors) which contain the unknown parameters. Finally $r$ is the number of modeled smoothed non-parametric functions to be used as constructed explanatory variables. The value of $m_{1}$ is found through cross-validation or a forward stage-wise strategy which stops when the model fit cannot be significantly improved. For large values of $m_{1}$ and an appropriate set of functions $f_{j}$, the PPR model is considered a universal estimator as it can estimate any continuous function in $\mathbf{R}^{\not}$. Thus this model takes the form of the basic additive model but with the additional $\beta_{j}$ component; making it fit $\beta_{j}^{\prime} x$ rather than the actual inputs $x$. The vector $\beta_{j}^{\prime} X$ is the projection of $X$ onto the unit vector $\beta_{j}$, where the directions $\beta_{j}$ are chosen to optimize model fit. The functions $f_{j}$ are unspecified by the model and estimated using some flexible smoothing method; preferably one with well defined second derivatives to simplify computation. This allows the PPR to be very general as it fits non-linear functions $f_{j}$ of any class of linear combinations in $X$.

For a given set of data $\left(y_{i}, x_{i}\right)$, the goal is to minimize the squared error

$$
S=\sum_{i=1}^{n}\left[y_{i}-\sum_{j=1}^{m_{1}} f_{j}\left(\beta_{j}^{\prime} x_{i}\right)\right]^{2}
$$

over the functions $f_{j}$ and vectors $\beta_{j}$. After estimating the smoothing functions $f_{j}$, one generally uses the Gauss-Newton iterated convergence technique to solve for $\beta_{j}$; provided that the functions $f_{j}$ are twice differentiable. It has been shown that the convergence rate, the bias and the variance are affected by the estimation of $\beta_{j}$ and $f_{j}$. It has also been shown that $\beta_{j}$ converges at an order of $n^{1 / 2}$, while $f_{j}$ converges at a slightly worse order. 